\title{
EDUCAÇÃO INTEGRAL E ATENDIMENTO EDUCACIONAL ESPECIALIZADO: COMO ESSAS POLÍTICAS SÃO IMPLEMENTADAS AO MESMO TEMPO?
}

\author{
Mariana da Cunha Sotero ${ }^{1}$ (D) \\ Eliana Briense Jorge Cunha ${ }^{1}$ (D) \\ Valéria Aroeira Garcia ${ }^{l}$ (D)
}

RESUMO: Esse artigo tem como propósito trazer problemáticas e levantar questóes acerca de quais tempos e espaços o atendimento educacional especializado vem ocupando nas escolas de educação integral. Não apresentamos respostas, mas a partir do cotidiano das escolas de educaçáo integral em suas organizaçóes para a realização do atendimento educacional especializado, trazemos perguntas e reflexóes sobre as dificuldades no atendimento à legislaçáo tanto do atendimento educacional especializado quanto da educaçáo integral, coadunando as necessidades das crianças e adolescentes público-alvo da educaçáo especial.

Palavras-chave: Atendimento educacional especializado. Educação especial. Escola de educação integral.

Full-time education and specialized educational care: how these policies are implemented at the same time?

ABSTRACT: This article aims to raise problems and questions about what time and spaces the Specialized Educational Care (SCE) are occupying in Full-time Education Schools.

${ }^{1}$ Rede Municipal de Educação - Campinas (SP), Brasil. E-mails: marianahcunha@gmail.com, elianacunhaid@yahoo.com.br, va_garcia@hotmail.com

DOI: $10.1590 / C C 0101-32622019219694$ 
The article does not offer answers, instead, it raises questions and considerations from the everyday life of Full-time Education schools in their organizations for the achievement of the SCE, as well as the difficulties in compliance from both the SCE and the education in line with the needs of children and adolescents, the target audience of special education.

Keywords: Specialized educational care. Special education. Full-time education school.

\section{INTRODUÇÃO}

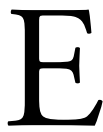

ste artigo tem como objetivo observar as relaçóes que têm se estabelecido entre a política de educação especial, especificamente em relação ao atendimento educacional especializado (AEE), e sua implementação no contexto da educação integral nas escolas de ensino fundamental, em geral identificadas como escola de tempo integral, em curso no Brasil. $\mathrm{O}$ estudo justifica-se pela relevância que a educaçáo integral e o atendimento educacional especializado têm no atual cenário das políticas educacionais e a necessidade de aprofundamento do conhecimento sobre como essas diretrizes educacionais recentes estáo sendo implementadas ao mesmo tempo.

Nesse contexto, faz-se necessário compreender como a legislação vem orientando e amparando os sistemas de ensino na implementação dessas duas políticas. Apresentamos a seguinte questáo como orientadora dessa investigação: no âmbito da legislaçáo educacional, em que tempo e espaço da proposta de educação integral o AEE deve ser desenvolvido?

\section{O ATENDIMENTO EDUCACIONAL ESPECIALIZADO NO ÂMBITO DAS POLÍTICAS DE EDUCAÇÃO ESPECIAL NA PERSPECTIVA DA EDUCAÇÃO INCLUSIVA}

A política de AEE nasce no bojo de políticas federais de radicalização da proposta pró-inclusão, a partir dos anos 2000, in- 
tensificando-se no governo de Luiz Inácio Lula da Silva (2003-2006; 2007-2010). Essa política prevê o acesso, a permanência e a aprendizagem de todos os alunos com deficiência, transtornos globais do desenvolvimento (TGD) e altas habilidades/superdotação (AH/SD) ${ }^{1}$ na classe comum (KASSAR, 2011).

Essa proposta visa superar a história da exclusão de qualquer proposta educacional desses sujeitos e da concepção e prática de educação especial, muito tímida no Brasil, organizada como AEE substitutivo, acontecendo predominantemente em escolas especializadas ou classes especiais. Nesse sentido, os estudos de Mazzota (1993) apontam três atitudes sociais que marcaram o tratamento dado às pessoas com deficiência: "marginalização, assistencialismo e educação/reabilitação" (MAZZOTA, 1993, p. 14).

A Política Nacional de Educação Especial na Perspectiva da Educação Inclusiva, de 2008 (PNEE-EI/08)² e a Convenção sobre os Direitos das Pessoas com Deficiência, de $2009^{3}$, representam marcos, pois defendem que a educação escolar desses alunos deve ocorrer na classe comum acompanhados, quando necessário, de serviços de apoios especializados e não admitem a oferta de ensino substitutivo realizado em classes especiais ou escolas exclusivamente especializadas.

$\mathrm{Na}$ Convenção sobre os Direitos das Pessoas com Deficiência fica estabelecido, em seu artigo 24, que os Estados Partes devem assegurar que: "As pessoas com deficiência não sejam excluídas do sistema educacional geral sob alegação de deficiência e que as crianças com deficiência não sejam excluídas do ensino primário gratuito e compulsório ou do ensino secundário, sob alegação de deficiência” (BRASIL, 2009b).

Ainda assim, os dados brasileiros do Censo Escolar de 2008, divulgados pelo Instituto Nacional de Estudos e Pesquisas Educacionais Anísio Teixeira (Inep) (BRASIL, 2008), evidenciaram a prevalência da política pró-inclusão dos alunos com deficiência, TGD e AH/SD, ao mostrarem que, "pela primeira vez em nossa história educacional, invertemos as curvas que retratam o atendimento desses alunos, com o fim do predomínio de matrículas em escolas exclusivas e classes especiais" (PRIETO, 2010, p. 67). 
A Lei no 13.005, de 25 de junho de 2014, que aprova o Plano Nacional de Educação (PNE) (2014-2024) e dá outras providências, estabelece como meta 4 desse plano:

Universalizar, para a população de 4 (quatro) a 17 (dezessete) anos com deficiência, transtornos globais do desenvolvimento e altas habilidades ou superdotação, o acesso à educaçáo básica e ao atendimento educacional especializado, preferencialmente na rede regular de ensino, com a garantia de sistema educacional inclusivo, de salas de recursos multifuncionais, classes, escolas ou serviços especializados, públicos ou conveniados (BRASIL, 2014a).

Desse modo, a presença do público-alvo da educaçáo especial nas classes comuns é uma realidade crescente, para a qual a política de educação especial na perspectiva da educação inclusiva prevê a garantia da oferta de serviços de apoio especializado, voltados para eliminar as barreiras que possam impedir o acesso, a permanência e a aprendizagem do público-alvo da educação especial na escola.

No contexto das políticas de educação inclusiva, o modelo de serviço de apoio especializado, amplamente financiado e articulado pelo governo federal por meio de programas - tais como o "Programa de implantação de salas de recursos multifuncionais" (SRM) (2005), o "Programa nacional de formação continuada de professores na educação especial e formaçáo de professores para o atendimento educacional especializado" (AEE) (2009) —, é o AEE complementar e/ou suplementar à escolarização, realizado em SRM, conforme descrevem os documentos que seguem:

Para a PNEE-EI/08 (2008): O atendimento educacional especializado tem como função identificar, elaborar e organizar recursos pedagógicos e de acessibilidade que eliminem as barreiras para a plena participação dos alunos, considerando suas necessidades específicas. As atividades desenvolvidas no atendimento educacional especializado diferenciam-se daquelas realizadas na sala de aula comum, 
não sendo substitutivas à escolarização. Esse atendimento complementa elou suplementa a formação dos alunos com vistas à autonomia e independência na escola e fora dela (BRASIL, 2008a, p. 9, grifos nossos).

Segundo o artigo $5^{\circ}$ da Resolução Federal no 4, de 2009, que institui diretrizes operacionais para o AEE na educação básica, modalidade educação especial:

O AEE é realizado, prioritariamente, na sala de recursos multifuncionais da própria escola ou em outra escola de ensino regular, no turno inverso da escolarização, não sendo substitutivo às classes comuns, podendo ser realizado, também, em centro de Atendimento Educacional Especializado da rede pública ou de instituiçóes comunitárias, confessionais ou filantrópicas sem fins lucrativos, conveniadas com a Secretaria de Educação ou órgão equivalente dos Estados, Distrito Federal ou dos Municípios (BRASIL, 2009a, grifos nossos).

E o Decreto Federal no 7.611/11 define que o AEE deve ser prestado das seguintes formas:

I. complementar à formação dos estudantes com deficiência, transtornos globais do desenvolvimento, como apoio permanente e limitado no tempo e na frequência dos estudantes às salas de recursos multifuncionais; ou

II. suplementar à formação de estudantes com altas habilidades ou superdotação (BRASIL, 2011).

Essa perspectiva de o AEE não substituir a escolarização na classe comum é ratificada pela forma de financiamento da matrícula dos alunos público-alvo da educação especial, que no Decreto Federal no 7.611/11 define que, para efeito da distribuiçáo dos recursos do Fundo de Manutenção e Desenvolvimento da Educação Básica e de Valorização dos Profissionais da Educação (FUNDEB), será admitida a 
dupla matrícula dos estudantes da educação regular da rede pública que recebem AEE, que implica o cômputo do estudante tanto na educação regular da rede pública quanto no AEE.

Toda legislação supracitada aponta que o AEE não pode de modo algum substituir o tempo nem o espaço do currículo escolar, e sim deve complementá-los ou suplementá-los, de modo a garantir a participação nas práticas curriculares da escola.

Ante essas diretrizes para o AEE e a política de educação integral em curso no Brasil, entendida como educação escolar de dia inteiro, construída e enriquecida por significativas possibilidades formativas (MOLL, 2012), a seguinte questão analítica se faz presente: o AEE é desenvolvido em qual tempo e espaço da proposta curricular de educação integral?

\section{BREVE CONTEXTUALIZAÇÃO LEGAL DA EDUCAÇÃO INTEGRAL}

A implementação do AEE como o serviço especializado precípuo da política de educação especial federal está em andamento ao mesmo tempo em que está em curso uma política de educação integral, cuja meta 6 do PNE (2014-2024) prevê “oferecer educação em tempo integral em, no mínimo, $50 \%$ (cinquenta por cento) das escolas públicas, de forma a atender, pelo menos, $25 \%$ (vinte e cinco por cento) dos(as) alunos(as) da educação básica” (BRASIL, 2014a).

Os dados do Censo Escolar (INEP, 2018) têm revelado aumento no número de matrículas em educação integral do ensino fundamental desde 2010, sendo que durante o ano de 2014 o crescimento foi de 45,2\%, em 2016 os dados caíram subitamente, mas em 2017 os números voltaram a crescer, aproximando-se do percentual de matriculados de 2015, o maior índice nesse período.

O debate da educação integral no Brasil teve, no século XX, marcos importantes: as escolas parque/escolas-classe concebidas por Anísio de Teixeira nos anos de 1940/1960 e os centros integrados de educação pública (CIEPs) idealizados por Darcy Ribeiro nos anos de 1980/1990 (GIOLO, 2012; MOLL, 2012). 
Além da ampliação da jornada escolar, que se fazia necessária como condição para uma formação mais abrangente, essas experiências propunham uma formação que abarcasse o campo da ciência, das artes, da cultura e do mundo do trabalho por meio do desenvolvimento físico, cognitivo, afetivo, político e moral, e que pudesse contribuir para a superação da desigualdade social mantida e reforçada pela cultura escolar (MOLL, 2012).

Essas foram experiências pontuais, que não fizeram parte de uma política educacional para a nação brasileira que, via de regra, foram descaracterizadas ou interrompidas sob alegaçáo principal de que eram onerosas para os cofres públicos (GIOLO, 2012), mas constituíram um legado que alimentou outras experiências locais, tais como a escola viva (Campinas, São Paulo), a escola candanga (Brasília, Distrito Federal), a escola plural (Belo Horizonte, Minas Gerais), a escola cidadã (Porto Alegre, Rio Grande do Sul), entre tantas outras, somadas às conferências brasileiras de educação e aos fóruns mundiais de educação.

Atualmente, o debate da educação integral em jornada ampliada ou da escola de educação integral ganha cena nos marcos legais federais e açóes indutoras claras de ampliação, qualificação e reorganização da jornada escolar diária (MOLL, 2012).

Em 1996, a Lei de Diretrizes e Bases da Educação Nacional (LDBEN/96) já apontava para educação integral no artigo 34, parágrafo segundo, que prevê-se que "o ensino fundamental será ministrado progressivamente em tempo integral, a critério dos sistemas de ensino"; e no artigo 87 , parágrafo $5^{\circ}$, que estabelece que "serão conjugados todos os esforços objetivando a progressão das redes escolares públicas urbanas de ensino fundamental para regime de escolas de tempo integral" (BRASIL, 1996).

A Lei Federal no 10.172, de 9 de janeiro de 2001, que aprovou o PNE 2001-2010, também apontou o direito à educaçáo integral e indica a ampliação do tempo na escola como um dos possíveis alicerces para construí-la, apresentando a seguinte definição: "expandir a escola de tempo integral, que abranja um período de pelo menos sete horas diárias" (BRASIL, 2001) (meta 21/ensino fundamental). Enquanto a LDBEN/96 associa a ampliação do tempo apenas ao ensino fundamen- 
tal, o PNE/2001-2010, com algumas restrições, vincula-o também à educação infantil (MENEZES, 2012).

Foi com o FUNDEB em 2007 que o governo federal de fato garantiu condições concretas para um processo real de implantação de escolas de tempo integral em âmbito nacional. Esse fundo avançou em relação às leis anteriormente mencionadas (LDB e PNE), entre outros aspectos, por associar o tempo integral a todas as etapas da educação básica (educação infantil, ensino fundamental e ensino médio) (MENEZES, 2012).

Além disso, o FUNDEB também se destacou por destinar recursos para as diferentes etapas, modalidades e tipos de estabelecimento de ensino da educação básica, incluindo, ineditamente, recursos para as matrículas em tempo integral. Para fins de recursos do FUNDEB, o Decreto no 6.253/2007 regulamentou a educação básica em tempo integral como sendo a "jornada escolar com duração igual ou superior a sete horas diárias, durante todo o período letivo, compreendendo o tempo total que um mesmo aluno permanece na escola ou em atividades escolares" (BRASIL, 2007), uma vez que era necessário estabelecer um limite mínimo de jornada escolar de educação integral para que os governos municipais e estaduais pudessem fazer jus ao recebimento de recursos relacionados ao empenho vinculado à sua implantação, já que existem experiências de educação em jornada ampliada com diferentes extensóes de carga horária (MENEZES, 2012).

Em 2008, o Programa Mais Educação foi lançado como estratégia intersetorial para indução da educação integral, promovendo a ampliação dos tempos, espaços e oportunidades educativas (MOLL, 2012, p. 133).

Portanto, a legislação sobre educação integral no Brasil ampara e fomenta uma política de ampliação da jornada e das oportunidades educativas para os alunos na escola. Ao mesmo tempo, o ordenamento legal concernente à educação especial prevê o AEE no contraturno escolar e não substitutivo à escolarização. Diante disso, questionamos: em que tempo e espaço é garantido o AEE ao aluno público-alvo da educação especial matriculado na educação integral que tem no mínimo uma jornada de sete horas diárias de aula? 


\section{EDUCAÇÃO INTEGRAL E ATENDIMENTO EDUCACIONAL ESPECIALIZADO: UMA TRAMA DE POSSIBILIDADES E DESAFIOS}

A legislação aponta que tanto o AEE quanto a educação integral são direitos das crianças e adolescentes e que não existem em detrimento um do outro, ou seja, não é porque o aluno está matriculado na educação integral que ele deixou de ter a necessidade e o direito ao AEE; e ao mesmo tempo, não é porque o aluno está matriculado no AEE que ele não tem direito à escola com jornada estendida.

Então, buscando na legislação orientaçóes sobre como organizar a oferta do AEE para crianças e adolescentes que estão na educação integral com uma jornada de atividades escolares de no mínimo sete horas diárias, localiza-se somente a Nota Técnica no 62/2014 (BRASIL, 2014b) do Ministério da Educação, Secretaria de Educação Continuada, Alfabetização Diversidade e Inclusão, Diretoria de Políticas de Educação Especial (MEC/SECADI/DPPEE), publicada em 10 de setembro de 2014, que compreende:

No que tange às escolas que ofertam educação em tempo integral, cabe a cada instituição prever em seu Projeto Politico Pedagógico, atividades articuladas ao atendimento educacional especializado, visando promover condiçóes de plena participação dos estudantes com deficiência, em igualdade de oportunidades com os demais estudantes (BRASIL, 2014b, grifo nosso).

Chama-nos a atenção a orientação dada às escolas de educação integral, de que devem explicitar em seu projeto pedagógico as especificidades, as necessidades e as condições para participação dos alunos público-alvo de educação especial, sobre as quais se sustenta e se articula o AEE. Essa orientação reafirma que ambos, AEE e educação integral, são direitos concomitantes, inclusive devem estar articulados, mas não explicita de que forma isso pode ser organizado do ponto de vista dos tempos e espaços, de modo que o AEE seja complementar ou suplementar e não substitutivo à escolarização. 
É importante destacar que a Nota Técnica no 62/2014/MEC/ SECADI/DPPEE (BRASIL, 2014b) extrapola a concepção de AEE de atendimento complementar e suplementar náo substantivo à escolarização para apoios e medidas especializadas no contexto da escola, que promovam e garantam a participação do aluno público-alvo da educação especial, ao afirmar:

Compete ao professor do AEE, com base no estudo de caso de cada estudante com deficiência, elaborar o Plano de AEE. Neste documento deve propor medidas de acessibilidade necessárias para garantir sua participação em todas as atividades escolares; orientaçôes aos professores, monitores e familiares, além de parcerias intersetoriais, entre outras (BRASIL, 2014b, ano, grifo nosso).

Essa orientação sobre a necessidade da educação especial articular as práticas da escola para garantir a acessibilidade mostra que, para além da oferta do AEE complementar e suplementar, a educação especial pode se efetivar por meio da oferta de serviços de apoio especializados voltados a eliminar as barreiras que possam obstruir o processo de escolarização de estudantes com deficiência ou TGD, que se dáo no tempo e espaço da jornada do aluno matriculado na educação integral.

Ainda que o direito à educação especial possa ser garantido por meio de outros apoios especializados (medidas de acessibilidade, adequação de recursos, orientação a professores etc.), possíveis no tempo e espaço da educaçáo integral, fica a lacuna, no âmbito das orientaçóes legais, sobre como é organizado e ofertado para o aluno que necessita de atividades de AEE complementar e suplementar e que se diferenciam daquelas desenvolvidas na sala de aula comum. Existem recursos que precisam de tempo e espaço para que os alunos aprendam a utilizá-los e para que tenham funcionalidade e garantam acessibilidade na realização das atividades de classe comum, como por exemplo, ensino e aprendizagem de Braille, do uso de tecnologias assistivas como linha Braille, lupa eletrônica, software etc. 
Observamos então, que no âmbito do ordenamento legal, não há uma regulamentação que defina em que tempo e espaço é garantido e organizado o AEE ao aluno público-alvo da educação especial matriculado na educação integral. A legislação aponta que tanto o AEE quanto a participação nas propostas curriculares são direitos do aluno, mas não regulamenta de que forma esses direitos devem ser exercidos no cotidiano das famílias e escolas.

Diante de tudo isso, defendemos que é a partir da análise de como as escolas de educação integral vêm se organizando para garantir o direito ao AEE aos alunos público-alvo da educação especial que poderemos ter indícios e referências de como essas duas políticas são implementadas ao mesmo tempo. Portanto, pesquisas que se debrucem sobre essa problemática se fazem urgentes para subsidiar a construção de orientaçóes e caminhos que contemplem as necessidades dos alunos, considerando que esses têm direito aos apoios especializados que necessitam, assim como direito à educação integral.

A seguir apontamos algumas problematizações que podem fomentar futuras reflexóes e novas elaboraçóes sobre a temática discutida neste artigo:

- Considerando que na educação integral o aluno tem seu turno ocupado de forma integral e que, além da ampliação da jornada escolar, a educação integral deve promover uma formação mais abrangente, que abarque o campo da ciência, das artes, da cultura e do mundo do trabalho, por meio do máximo de desenvolvimento possível das dimensóes física, cognitiva, afetiva, política e moral para o exercício da autonomia e cidadania, compreendemos que não há atividades de contraturno que caibam na concepção de educação integral. Assim, o AEE e os outros apoios especializados que o aluno necessita constituem mais campo/serviço para formação integral dos alunos. Portanto, o AEE deve fazer parte e estar de fato integrado à proposta de educação integral. $\mathrm{O}$ que leva à seguinte questão para análise: como as escolas de educação integral estão organizando seus currículos de modo a contemplar o AEE e os apoios especializados que os alunos necessitam?; 
- As alunas e os alunos das escolas de educação integral têm o direito de estarem presentes e participarem de todos os tempos curriculares, e também têm o direito e necessitam do AEE. O que isso pode significar? Em que tempo pode acontecer o AEE, se as alunas e alunos estão envolvidos com seu tempo integral na proposta curricular da escola?;

- Considerando que educação especial se concretiza por meio da oferta de uma gama de serviços e apoios especializados transversais e complementares à escolarização; e que eles devem atender às necessidades dos alunos de modo a promover sua participação nas práticas curriculares da escola, a avaliaçáo pedagógica dos alunos e do contexto deve ocupar papel central para indicação dos apoios mais adequados e para organização dos tempos e espaços para esses apoios acontecerem;

- Cabe lembrar que AEE e educação integral estão no bojo de outros direitos das crianças e adolescentes, explicitados na Constituição Federal e no Estatuto da Criança e do Adolescente, como atendimentos clínicos e terapêuticos que também compóem a rotina das crianças e adolescentes, portanto, a organizaçáo dos tempos e espaços do AEE e da educação integral deve considerar também as outras necessidades das crianças e adolescentes.

\section{REFERÊNCIAS}

BRASIL. Congresso Nacional. Plano Nacional de Educação: Lei no 10.172, de 9 de janeiro de 2001. Brasília: Senado Federal, 2001.

- Ministério da Educação. Conselho Nacional de Educação. Câmara de Educação Básica. Resolução no 4, de 2 de outubro de 2009. Institui diretrizes operacionais para o atendimento educacional especializado na Educação Básica, modalidade Educação Especial. Brasília: MEC/CNE/CEB, 2009a.

- Ministério da Educação. Secretaria de Educação Continuada, Alfabetização, Diversidade e Inclusão. Nota Técnica $n^{\circ}$ 62. Organização do atendimento educacional especializado na educaçáo integral. Diretoria de Políticas de Educação especial. Brasília, 2014b. 
BRASIL. Presidência da República. Decreto $n^{\circ}$ 6.253, de 13 de novembro de 2007. Dispóe sobre o Fundo de Manutenção e Desenvolvimento da Educação Básica e de Valorização dos Profissionais da Educação - FUNDEB, regulamenta a Lei no 11.494, de 20 de junho de 2007, e dá outras providências. 2007.

. Presidência da República. Decreto no 6.571, de 17 de setembro de 2008. Dispóe sobre o atendimento educacional especializado, regulamenta o parágrafo único do art. 60 da Lei no 9.394, de 20 de dezembro de 1996, e acrescenta dispositivo ao Decreto no 6.253, de 13 de novembro de 2007. 2008.

Presidência da República. Decreto no 6.949/09, de 25 de agosto de 2009. Promulga a Convenção Internacional sobre os Direitos das Pessoas com Deficiência e seu Protocolo Facultativo, assinados em Nova York, em 30 de março de 2007. 2009b.

. Presidência da República. Decreto no 7.611 , de 17 de novembro de 2011. Dispóe sobre a educação especial, o atendimento educacional especializado e dá outras providências. Diário Oficial da União, Brasília, 2011.

. Presidência da República. Lei no 9.394, de 20 de dezembro de 1996. Estabelece as diretrizes e bases da educação nacional. 1996.

. Presidência da República. Lei no 12.796, de 4 de abril de 2013. Altera a Lei no 9.394, de 20 de dezembro de 1996, que estabelece as diretrizes e bases da educação nacional, para dispor sobre a formação dos profissionais da educação e dar outras providências. Brasília, 2013.

. Presidência da República. Lei no 13.005, de 25 de junho de 2014, que aprova o Plano Nacional de Educação (PNE) (2014-2024) e dá outras providências. 2014 a.

Secretaria da Educação Especial. Política Nacional de Educação Especial na perspectiva da educação inclusiva. Revista da Educação Especial, v. 4, n. 1, jan./jun. 2008.

GIOLO, J. Educação de tempo integral: resgatando elementos históricos e conceituais para o debate. In: MOLL, J. et al. Caminhos da Educação Integral no Brasil: direito a outros tempos e espaços educativos. Porto Alegre: Penso, 2012. p. 94-104.

INSTITUTO NACIONAL DE ESTUDOS E PESQUISAS EDUCACIONAIS ANÍSIO TEIXEIRA (INEP). Censo escolar, 2010. Brasília: Ministério da Educação, 2018.

KASSAR, M. de C. M. Educação especial na perspectiva da educação inclusiva: desafios da implantação de uma política nacional. Educar em Revista, 
Curitiba, n. 41, p. 61-79, jul./set. 2011. http://dx.doi.org/10.1590/S0104$\underline{40602011000300005}$

MAZZOTA, M.J.S. Trabalho docente e formação de professores para a educação especial. São Paulo: EPU, 1993.

MENEZES, J. Educação em tempo integral: direito e financiamento. Educar em Revista, Curitiba, v. 28, n. 45, p. 137-152, jul/set. 2012. http://dx.doi. org/10.1590/S0104-40602012000300010

MOLL, J. A agenda da educaçáo integral: compromissos. In: MOLL, J. et al. Caminhos da Educação Integral no Brasil: direito a outros tempos e espaços educativos. Porto Alegre: Penso, 2012. p. 129-146.

PRIETO, R.G. Políticas de inclusão escolar no Brasil: sobre novos/velhos significados para educação especial. In: MENDES, E.G. et al. das margens ao centro: perspectivas para as políticas e práticas educacionais no contexto da educação especial inclusiva. Araraquara: Junqueira \& Marin, 2010. p. 61-78.

\section{NOTAS}

1. Para esta pesquisa, consideramos como população-alvo da educação especial os alunos com deficiência, TGD e AH/SD, tal como definida pelo Decreto Federal no 7.611, de 17 de novembro de 2011, e pela Lei Federal no 12.796, de 4 de abril de 2013 (BRASIL, 2013), que reformula a Lei Federal no 9.394, de 20 de dezembro de 1996.

2. A PNEE-EI/08 foi elaborada pelo grupo de trabalho nomeado pela Portaria Ministerial no 555, de 5 de junho de 2007, prorrogada pela Portaria no 948, de 9 de outubro de 2007.

3. A Convenção sobre os Direitos das Pessoas com Deficiência e seu Protocolo Facultativo, assinados em Nova York, em 30 de março de 2007, foi aprovada como emenda constitucional, por meio do Decreto Legislativo $n^{\circ} 186$, de 9 de julho de 2008 , conforme o procedimento do $\$ 3^{\circ}$ do art. $5^{\circ}$ da Constituição e promulgada pelo Decreto Federal no 6.949, de 25 de agosto de 2009.

Recebido em 20 de março de 2019.

Aprovado em $1^{\circ}$ de julho de 2019.

(C) 2019 Centro de Estudos Educação e Sociedade - CEDES Este é um artigo de acesso aberto distribuído nos termos de licença Creative Commons. 